\title{
A HISTÓRIA DA CAMPANHA DE CANUDOS NARRADA COMO DRAMA
}

\author{
Regina Simon da SILVA \\ Universidade Federal do Rio Grande do Norte \\ reginasimon@ig.com.br
}

Resumo: Este artigo apresenta uma análise do romance Os sertões (1902), de Euclides da Cunha, a partir da observação do fato histórico que motiva a escrita do livro e a forma dramática como ele é contado. Procura-se pôr em evidência o discurso literário como metáfora do eterno, pois é por meio dele que o particular se universaliza e renasce, todas as vezes em que é lido pelas novas gerações.

Palavras-chave: Os sertões. Literatura e história. Discurso literário. Metáfora.

\begin{abstract}
This article presents an analysis of the novel Os sertões, by Euclides da Cunha, from the observation of the historical fact that motivates the writing of the book and how dramatically this historical fact is told. It tries to highlight the literary discourse as metaphors of the eternal, for it is through this discourse that particular aspects become universal and are reborn every time the book is read by new generations.
\end{abstract}

Keywords: Os sertões Literature and history. Literary discourse. Metaphors.

\section{Introdução}

Segundo Walnice Nogueira Galvão (1994), costuma-se colocar Euclides da Cunha sob o "incômodo rótulo do pré-modernismo" por não haver uma melhor categoria. Para ela, a rejeição dispensada pelo modernismo se deve à retórica do excesso, ao registro grandiloquente de Euclides.

Porém, na sua concepção, Euclides foi um "abridor de caminhos", uma vez que o modernismo dará continuidade a alguns dos questionamentos levantados por ele. Muitos dos temas abordados em Os sertões serão focos de discussão a se destacar "na produção intelectual e artística do século XX, ao debruçar-se sobre o negro, o índio, os pobres, os sertanejos, a condição colonizada, a religiosidade popular, as insurreições, o subdesenvolvimento e a dependência" (GALVÃO, 1994, p. 618).

Se, por um lado, a temática abordada em Os sertões aproxima ou mesmo inclui Euclides da Cunha no movimento modernista, o discurso, por outro, o afasta. No entanto, é exatamente esse o ponto que motiva esse trabalho: o discurso literário, a 
forma como um fato histórico extrapola seu contexto histórico para se configurar ficção, eternizando-se através da metáfora literária.

Para o desenvolvimento desse estudo, procuramos unir as duas proposições - a história que motiva o livro e a forma dramática como ela é contada. Com essa finalidade, faremos uma breve análise do Diário de Canudos, obra que reúne artigos De Euclides da Cunha para, em seguida, analisar sua obra capital, observando a ficcionalização da história, em sua forma dramática.

\section{História ou estória da campanha de Canudos?}

Não nos parece pertinente discutir neste estudo a natureza da obra de Euclides da Cunha, uma vez que partimos da simples conclusão de que se o seu livro fosse apenas uma obra histórica, certamente, já teria desaparecido, ou então, despertaria o interesse apenas nos historiadores, fato que, definitivamente, é incorreto afirmar. No entanto, ao investigarmos a obra de Hayden White, Trópicos do discurso: ensaios sobre a crítica da cultura (1994), que trata do discurso do historiador, constatamos que este também vive o impasse quanto à natureza de seus escritos, voltando à concepção de que "a história é uma semiciência, de que os dados históricos não se prestam à 'livre' manipulação artística e de que a forma das suas narrativas não é uma questão de escolha, mas é exigida pela natureza da própria matéria histórica" (WHITE, 1994, p. 39). Nesta concepção, o discurso histórico seria marcado por uma escrita mais ou menos homogênea, já que os fatos históricos seriam abordados da mesma forma por historiadores diferentes.

Discordamos dessa conclusão. Ainda que essas narrativas sejam escritas com uma linguagem a mais referencial possível, não podemos esquecer-nos de que o objeto descrito - no caso o fato histórico - passa pela interpretação do historiador, ou seja, pelo indivíduo que descreve os fatos e, dificilmente, esses discursos serão iguais. A matéria será a mesma, mas a forma de narrar respeitará o estilo de escrever de cada um.

Como essa questão parece não ter consenso, os teóricos contemporâneos vêm tentando solucionar de duas maneiras o problema do status epistemológico da história. De modo geral, dividiram-no em dois grupos: 
Um grupo, adotando uma visão positivista da explicação, afirmou que os historiadores explicam os acontecimentos passados somente na medida em que conseguem identificar as leis de causalidade que regem os processos nos quais ocorrem os eventos. Outro grupo, adotando uma postura um pouco mais literária, sustentou que os historiadores explicam os eventos que compõem as suas narrativas por meios especificamente narrativos de codificação, isto é, descobrindo a estória que está encerrada nos eventos ou por detrás deles e contandoa de uma maneira que um homem medianamente culto possa entender (WHITE, 1994, p. 69-70).

Esses teóricos não deixam de ressaltar que, apesar do caráter "literário" do segundo grupo, isso não invalida o seu trabalho, não deve ser considerado não científico ou anticientífico.

Apoiamo-nos nessas discussões desenvolvidas até aqui para dizer que se Euclides procurou descobrir a estória que estava encerrada no evento de Canudos ou por detrás dele para escrever a sua narrativa, ele o fez com maestria, evitando, assim, que a história de Canudos caísse no ostracismo ou que fosse apagada para sempre da memória do brasileiro, assim como o foi o povoado de Canudos com a construção da represa naquela região dos sertões nordestinos.

\section{O roteiro de $O$ s sertões}

Denominamos esse tópico "roteiro" para fazer jus ao tema do trabalho, mas também poderíamos chamá-lo de "matéria prima" de Os sertões. Trata-se do texto Canudos: Diário de uma Expedição (1939), narrativa escrita em primeira pessoa - o que permite ao leitor uma aproximação ao texto narrado -, em que se encontram reunidos os artigos escritos por Euclides da Cunha para o jornal $O$ Estado de São Paulo durante o período em que foi correspondente de guerra.

Naquelas páginas encontramos o estrato do que mais tarde viria a ser Os sertões. A leitura do Diário é tão envolvente quanto a de Os sertões, principalmente porque o narrador nos descreve em que condições produz a narrativa: "Escrevo rapidamente, direi mesmo, vertiginosamente, acotovelado a todo instante por passageiros que irradiam em todas as direções sobre o tombadilho [...]” (CUNHA, 1966, p. 493), palavras escritas nos primeiros momentos da viagem, enquanto se dirigia à Bahia, ou então, quando já se encontrava no sertão, no povoado de Tanquinho: "São dez horas da noite. Traço 
rapidamente estas notas sob a ramagem opulenta de um juazeiro, enquanto, em torno, todo o acampamento dorme" (CUNHA, 1966, p. 537); e, já no calor da luta, em Canudos: "Com relativa comodidade escrevo na mesa da farmácia anexa ao hospital militar. Em frente levantam-se barracões repletos de feridos e doentes e cheios de lamentos mal abafados, de dores cruciantes (...). Já me vou afeiçoando a esta orquestra estranha" (CUNHA, 1966, p. 558).

Assim como o fará mais tarde em Os sertões, Euclides esclarece, nos textos de sua correspondência, que muito do que ele narra são histórias que ouviu contar: "Estas e outras histórias, contam-nas aqui os soldados, colaboradores inconscientes das lendas que envolverão mais tarde esta campanha crudelíssima” (CUNHA, 1966, p. 514). Desconfiado, justifica que em breve estará dando conta da história de que será testemunha: "Creio que partiremos afinal por estes dias. Ajuizarei então, in sito, acerca do que até agora tenho sabido através de narrativas que nem sempre se ajustam nas mesmas conclusões" (CUNHA, 1966, p. 520).

A maior parte dos temas e episódios da Guerra de Canudos abordados em $O s$ sertões pode ser identificada em seus artigos. A descrição da terra, comparando-a com as das regiões do sul e do litoral; a descrição dos habitantes da região sertaneja e a formação da miscigenação; a oposição civilização/barbárie - litoral/sertão, ressaltando os anos de desenvolvimento que separam essas regiões brasileiras, entre outros.

É óbvio que notamos um Euclides sucinto, que não se detém detalhadamente em cada um desses aspectos. Porém, podemos antecipar o fervor com que escreverá sua obra futuramente, pois, apesar da sua função no momento ser a de um correspondente, sua narrativa é envolvente e vibrante, como podemos ver nesta descrição:

Apenas num e noutro ponto como variante sinistra: por um requinte de perversidade satânica os jagunços dispuseram em série nas duas bordas do caminho as ossadas dos mortos de anteriores expedições. Dólmãs, bonés, galões, talins, calças vermelhas rutilantes, amplos capotes, camisas em pedaços, selins e mantas, pendurados nos galhos das árvores, oscilavam lugubremente sobre a cabeça do viajante que passa, aterrado, atravessando entre duas fileiras de caveiras adrede dispostas, enfileiradas aos lados. Ё um quadro pavoroso, capaz de perturbar a alma mais robusta. $\mathrm{O}$ malogrado Coronel Tamarindo - um velho soldado jovial como havia poucos - foi reconhecido pela farda nesse cenário fantástico; sem cabeça, espetado num galho seco de angico e tendo sobre os ombros descarnados, pendido como um 
cabide, descendo-lhe, pelo esqueleto abaixo, o dólmã (CUNHA, 1966, p. 520).

Ou então, na cena sinistra da chegada de alguns prisioneiros à região de Queimadas:

\begin{abstract}
Acabam de chegar, há meia hora, nove prisioneiras; duas trazem ao seio crianças de pouco meses, mirradas como fetos; acompanham-nas quatro pequenos de três a cinco anos. $\mathrm{O}$ menor de todos, chama-se José. Assombra. Traz à cabeça, descendo-lhe até os ombros, um boné de soldado. O boné largo e grande demais oscila a cada passo; alguns circunstantes têm a coragem singular de rir - a criança volve o rosto, procurando vê-los e os risos cessam: a boca é uma chaga, foi atravessada por uma bala! (CUNHA, 1966, p. 536).
\end{abstract}

Acompanhamos um Euclides poético e emotivo, no âmago de uma guerra cruel e sangrenta, e quem impõe ao narrador essa transformação é a "mãe natureza", que com toda a sua rudeza fascina o correspondente:

Não há manhãs que se comparem às de Canudos; nem as manhãs sulmineiras nem as manhãs douradas do planalto central de São Paulo se equiparam às que aqui se expandem num firmamento puríssimo, com irradiações fantásticas de apoteose. Douram-se primeiro as cristas altas do Cocorobó, Paço de Cima e Canabrava e a onda luminosa do dia sulca-lhe, lentamente ascendendo, os flancos abruptos e ásperos semelhando uma queimada longínqua, nas serras. A orla iluminada amplia-se, vagarosamente, descendo pelos contrafortes das montanhas fimbriadas de centelhas... (CUNHA, 1966, p. 562).

Os acontecimentos que Euclides descreve, como testemunha ocular ou não, são fortes e chocam. O mundo fantástico da literatura agora é compreendido, pois a "visão do inferno se apresenta diante dos olhos":

Quando a uma hora da tarde contemplei o quadro emocionante e extraordinário, compreendi o gênio sombrio e prodigioso de Dante. Porque há uma coisa que só ele soube definir e que eu vi naquela sanga estreitíssima, abafada e ardente, mais lúgubre que o mais lúgubre vale do Inferno: a blasfêmia orvalhada de lágrimas, rugindo nas bocas simultaneamente com os gemidos da dor e os soluços extremos da morte (CUNHA, 1966, p. 569). 
Fica claro para o leitor que o discurso de Euclides não teria essa força se o inimigo enfrentado não fosse forte e guerreiro como o foi. As forças republicanas subestimaram o adversário que se agigantou, numa luta desigual:

Há três dias acreditei que os nossos antagonistas não poderiam resistir três horas, esmagados numa brusca apertura do cerco, mas lá estão, indomáveis, num círculo estreitíssimo, visados constantemente por mil e tantas carabinas prestes a disparar - e não cedem. São incompreensíveis quase tais lances de heroísmo (CUNHA, 1966, p. 558).

Esses são apenas alguns dos muitos momentos que merecem um comentário e que vêm confirmar a ideia de que a vida real ofereceu a Euclides matéria suficiente para a produção de sua obra, com um detalhe ainda a ser acrescido: a Campanha de Canudos reproduz, com requinte de ações e emoção, uma verdadeira tragédia, mas quem a descreve declara: "Felizes os que não presenciaram nunca um cenário igual [...]" (CUNHA, 1966, p. 570).

Em determinado momento Euclides reconhece o caráter um tanto eloquente de seu discurso e tenta justificar-se afirmando que, provavelmente, é fruto do impulso do momento:

É possível que das notas rápidas de um diário, em que os períodos não se alinham corretos, disciplinados e calmamente meditados, ressumbrem exageros; é possível mesmo que eu os releia mais tarde com surpresa. Mas nessa ocasião estarei como os que agora o leem fora do círculo hipnótico de um entusiasmo sincero e não terei, como agora o tenho, diante de mim, a visão deslumbrante de uma pátria regenerada - ao ver passar, ao ritmo retumbante dos tambores, os titãs bronzeados que chegam do Norte numa revivescência animadora de energias [...] (CUNHA, 1966, p. 508).

O distanciamento do drama de Canudos não alterou o entusiasmo sincero, no entanto, o objeto desse entusiasmo mudou bastante: os "titãs bronzeados" não serão mais os soldados que chegam, mas os jagunços que defendem seus lares. O turbilhão de informações e visões coletadas in sito invadiu a sua alma e transbordou, formando essa grande obra que é Os sertões, não apenas pelo número de páginas, como também pela qualidade do texto. Usando uma imagem marcante do sertão para fazer uma analogia, podemos dizer que o Diário de Euclides representa o Vaza-Barris na seca e Os sertões 
configura este mesmo rio no esplendor das grandes cheias. Ambos os textos são importantes e o que vimos aqui é apenas uma prévia do intenso drama que se representará a seguir.

\section{Canudos: a representação de um drama}

Há um quadro de Klee que se chama Angelus Novus. Representa um anjo que parece querer afastar-se de algo que ele encara fixamente. Seus olhos estão escancarados, sua boca dilatada, suas asas abertas. $O$ anjo da história deve ter esse aspecto. Seu rosto está dirigido para o passado. Onde nós vemos uma cadeia de acontecimentos, ele vê uma catástrofe única, que acumula incansavelmente ruína sobre ruína e as dispersa a nossos pés. Ele gostaria de deter-se para acordar os mortos e juntar os fragmentos. Mas uma tempestade sopra do paraíso e prende-se em suas asas com tanta força que ele não pode mais fechá-las. Essa tempestade o impele irresistivelmente para o futuro, ao qual ele vira as costas, enquanto o amontoado de ruínas cresce até o céu. Essa tempestade é o que chamamos progresso.

Walter Benjamin

Parece-nos apropriada a citação de Walter Benjamin (1987), pois é assim que vemos Os sertões, como o filósofo via o Angelus Novus, de Paul Klee. A narrativa de Euclides nos obriga a lançar um olhar ao passado. Parafraseando o texto de Juan Antonio Hernández (2004), provavelmente o anjo benjaminiano gostaria de deter-se para acordar os jagunços e juntar os fragmentos, restaurar as ruínas, resgatar a memória dos vencidos. Também é bastante provável que Euclides não tivesse essa intenção ao escrever o seu livro, uma vez que na nota preliminar este diz: "o jagunço destemeroso, o tabaréu ingênuo e o caipira simplório, serão em breve relegados às tradições evanescentes, ou extintos" (CUNHA, 2001, p. 13), anunciando a tempestade que impelia irresistivelmente o Brasil para o futuro. Porém, o progresso chegou, Canudos não existe mais, mas o jagunço, o tabaréu, o caipira, ainda resistem e mantêm muitas das tradições do passado.

Por isso, o leitor atual, ao ler Os sertões, deverá analisá-lo à luz da atualidade, vendo-o como obra literária que é, pois tão importante quanto o que motivou essa obra é a forma como Euclides a escreveu e lhe deu vida, foi isso que a fez transcender o tempo. O leitor, ao abrir as páginas de Os sertões, vê-se diante de dois textos: o primeiro é a narrativa em si, que conta os fatos ocorridos no sertão nordestino nos fins do século 
XIX; o outro é o grande drama que se representa. Intencionalmente ou não, Euclides constrói o seu teatro e o leitor passa, neste momento, a espectador de uma representação.

A divisão da obra em três partes pode assim ser compreendida: terra/cenário; homem/personagens; luta/atuação dos atores.

Logo nas primeiras páginas, o narrador - ou diretor? - põe-se a descrever o cenário onde mais tarde será representado o espetáculo. Terra árida, sofrida, de difícil acesso e trato, sempre foi evitada pelos viajantes que por aí passavam, "contorneavam sempre, evitando-a sempre, a paragem sinistra e desolada, subtraindo-se a uma travessia torturante" (CUNHA, 2001, p. 24).

O teatro ao ar livre encontra na própria natureza os elementos para compor a "casa" onde será encenado o drama, e, montanhas se transformam em cortinas que se abrem para contar ao mundo uma história: "Dominante sobre a várzea que se estende para sudeste, com a linha de cumeadas quase retilínea, o seu enorme paredão, vincado pelas linhas dos estratos, expostas pela erosão eólia, afigura-se cortina de muralha monumental" (CUNHA, 2001, p. 26).

Através dos olhos do narrador, o leitor visualiza o novo cenário, “ao deixar as perspectivas majestosas, que se desdobram ao sul, trocando-as pelos cenários emocionantes daquela natureza torturada" (CUNHA, 2001, p. 29), e deixa para trás a paisagem exuberante do sul para penetrar nas terras de outro Brasil.

O contraste norte/sul, sertão/litoral é evidente e será tema recorrente em toda a narrativa. Mas o sertão não é feito só de pedras, poeira e arbustos, a natureza é sábia e guarda consigo segredos que emocionam o homem. É assim que Euclides descreve a transformação da natureza depois de uma chuva, um momento mágico em que só a poesia consegue dizer o que os olhos veem: "E ao tornar da travessia o viajante, pasmo, não vê mais o deserto. Sobre o solo, que as amarílis atapetam, ressurge triunfante a flora tropical. É uma mutação de apoteose" (CUNHA, 2001, p. 51). A vegetação, antes com aspecto sombrio, ganha novo fôlego: "abrolhando em folhas, que passam em fugitivos cambiantes de um verde pálido ou róseo vivo dos rebentos novos, atraem melhor o olhar, são a nota mais feliz do cenário deslumbrante. E o sertão é um paraíso [...]" (CUNHA, 2001, p. 53). 
Um paraíso repleto de antíteses, "barbaramente estéreis; maravilhosamente exuberantes" (CUNHA, 2001, p. 55). Euclides não se esconde e denuncia a ação do explorador como o grande causador do deserto que, "abrindo-lhes a estrada e devastando a terra, o mesmo batedor sinistro, o incêndio" (CUNHA, 2001, p. 58), provocado pelo homem que explora a terra.

Dessa forma termina a primeira parte de Os sertões e nos tornamos conhecedores do cenário onde os vários personagens atuarão.

Em sua segunda parte - "O Homem" - Euclides passa a descrever os atores que representarão o drama. Nessa etapa da narrativa, os paralelos traçados entre norte/sul se intensificam e as diferenças se agigantam. Como entrarão em cena tipos díspares Euclides passa a descrevê-los: primeiro os personagens sertanejos e depois os personagens do sul, que virão para combater os primeiros.

No seu discurso inicial, Euclides perscruta a gênese das raças mestiças no Brasil. Mas não nos cabe aqui julgar a precisão do seu trabalho como etnólogo, o que nos interessa é a descrição, a princípio depreciativa que o narrador traça do sertanejo e que, como veremos mais tarde, sofrerá uma mutação:

\footnotetext{
A mistura das raças mui diversas é, na maioria dos casos prejudicial. Ante as conclusões do evolucionismo, ainda quando reaja sobre o produto o influxo de uma raça superior, despontam vivíssimos estigmas da inferior. A mestiçagem extremada é um retrocesso (CUNHA, 2001, p. 100).
}

O narrador os descreve como uma subcategoria, expondo o problema social, pois a não integração desses mestiços com a parte "civilizada" do Brasil também é uma maneira de eliminá-los, de destruí-los: "é que neste caso a raça forte não destrói a fraca pelas armas, esmaga-a pela civilização" (CUNHA, 2001, p. 102).

Porém, Euclides se contradiz quanto ao benefício que a civilização e o desenvolvimento trazem para o indivíduo, ao afirmar que "o abandono em que jazeram teve função benéfica. Libertou-os da adaptação penosíssima a um estágio social superior, e, simultaneamente, evitou que descambassem para as aberrações e vícios dos meios adiantados" (CUNHA, 2001, p. 103).

Notamos que, antes mesmo de começar a "Luta", Euclides já dá indícios de reconhecimento da bravura do sertanejo na luta pela vida, "o sertanejo é, antes de tudo, 
um forte" (CUNHA, 2001, p. 105), sua aparência feia e frágil é uma adaptação ao meio, sua inércia engana os forasteiros, "é desgracioso, desengonçado, torto, entretanto, toda esta aparência de cansaço ilude" (CUNHA, 2001, p. 105-6).

A descrição do sertanejo também dá mostras da dificuldade que o exército enfrentará, antecipando o drama da adaptação à terra, o maior inimigo das forças republicanas. Vemos, nessas imagens, a primeira exposição do sertanejo como o grande guerreiro:

O seu aspecto recorda, vagamente, à primeira vista, a de guerreiro antigo exausto da refrega. As vestes são uma armadura. Envolto no gibão de couro curtido, de bode ou de vaqueta; apertado no colete também de couro; calçando as perneiras, de couro curtido ainda, muito justas, cosidas às pernas e subindo até as virilhas, articuladas em joelheiras de sola; e resguardados os pés e as mãos pelas luvas e guarda-pés de pele de veado - é como a forma grosseira de um campeador medieval desgarrado em nosso tempo (CUNHA, 2001, p. 108).

A descrição do gaúcho é de um guerreiro valente, elegante, sobre o cavalo nas pradarias dos pampas e, comparando-os, Euclides conclui que "o jagunço é menos teatralmente heroico; é mais tenaz, é mais resistente, é mais perigoso, é mais forte; é mais duro" (CUNHA, 2001, p. 110).

Euclides não deixa de fazer uma análise da motivação religiosa do grupo, tema que nos levaria a uma outra direção, por isso deteremos nosso olhar apenas na conclusão a que chega: "a sua religião é, como ele - mestiça" (CUNHA, 2001, p. 124). Explicando, mais adiante, o seu raciocínio quanto à religiosidade do sertanejo, Euclides dirá: “Todas as crenças ingênuas, do fetichismo bárbaro às aberrações católicas, todas as tendências impulsivas das raças inferiores, livremente exercitadas na disciplina da vida sertaneja, se condensavam no seu misticismo feroz e extravagante" (CUNHA, 2001, p. 132-3).

Euclides segue descrevendo o seu elenco, detendo-se na figura de Antônio Conselheiro, que "era o profeta, o emissário das alturas, transfigurado por ilapso estupendo, mas adstrito a todas as contingências humanas, passível do sofrimento e da morte, e tendo uma função exclusiva: apontar aos pecadores o caminho da salvação" (CUNHA, 2001, p. 134). 
O sertanejo, traçado até agora de forma coletiva, ganha alguns destaques nas figuras individuais de José Venâncio, Joaquim Tranca-Pés, Antônio Beato, João Abade, Norberto, Chico Ema, personagens que sobressaem em "A luta", embora a figura coletiva do jagunço seja o grande destaque, no momento em que os personagens começam a representar o drama que domina mais dessa metade do livro que Euclides intitula "A luta".

Chegando ao capítulo de "A luta", o narrador corrobora a ideia anterior de que a terra é o grande antagonista que os militares enfrentarão. O leitor atento já prevê a dificuldade que espera os militares, pois o sertanejo conhece melhor o cenário onde a ação se desenrolará e, portanto, movimenta-se com maior desenvoltura, sabe o momento certo em que deve atuar com maior energia e quando deve poupá-la:

As caatingas são um aliado incorruptível do sertanejo em revolta. Entram também de certo modo na luta. Armam-se para o combate; agridem. Trançam-se, impenetráveis, ante o forasteiro, mas abrem-se em trilhas multivias, para o matuto que ali nasceu e cresceu (CUNHA, 2001, p. 203).

Adaptado ao meio, o sertanejo é como um camaleão, mimetiza-se, assustando o forasteiro que é tomado pelo medo "ante o antagonista que vê e não é visto" (CUNHA, 2001, p. 204). Ao contrário do sertanejo, a força militar desconhece o palco onde atua e, vendo-se tomada pela sede e pela fome, não encontrando em seu redor a mínima condição de sobrevivência, "foge ante o flagelo iminente" (CUNHA, 2001, p. 207), enquanto aquele, "segue firme na rota como quem conhece a palmo todos os recantos do imenso lar sem teto" (CUNHA, 2001, p. 207), ou do anfiteatro.

A travessia de Combaio termina em desvantagem para as forças do Sul, que não contavam com os imprevistos que surgiram, acreditando na sua superioridade intelectual e bélica para vencer a luta, descuidando-se na atuação. Daí o tom irônico empregado por Euclides na descrição do desfecho:

Num tripúdio de símios amotinados pareciam haver transmudado tudo aquilo num passatempo doloroso e num apedrejamento. Desfilavam pelos altos em corrimaças turbulentas e ruidosas. Os lutadores embaixo seguiam como atores infelizes, no epílogo de um drama mal representado (CUNHA, 2001, p. 238). 
Com a expedição Moreira César não é diferente. Os erros e a má representação se repetem e o fato de não saberem lidar com o desconhecido reverte a situação, favorecendo o sertanejo: “os jagunços à porta assaltavam-no, e invertiam-se os papéis, revivendo o conflito, até baquear no chão - cosido a faca e moído a pauladas, pisado pela alpercata dura, o lutador imprudente" (CUNHA, 2001, p. 280).

À medida que a guerra torna-se mais violenta, notamos que no discurso de Euclides se intensificam as palavras que aludem ao mundo do teatro: "mais uma vez o drama temeroso da guerra sertaneja tinha o desenlace de uma peleada lúgubre" (CUNHA, 2001, p. 289). Mais adiante, nos conta o narrador: "abriu-se de improviso um episódio épico" (CUNHA, 2001, p. 291).

A fuga era inevitável. O sertão agora ganha novo colorido, transforma-se, mas dessa vez o motivo não é a chuva que traz vida, mas sim da morte:

[...] a caatinga mirrada e nua, apareceu repentinamente desabrochando numa florescência extravagantemente colorida no vermelho forte das divisas, no azul desmaiado dos dólmãs e nos brilhos vivos das chapas dos talins e estribos oscilantes (CUNHA, 2001, p. 254).

Euclides confere um tom eloquente à linguagem, pois somente assim o leitor/ espectador conseguirá reconstruir mentalmente a imagem que ele perfaz:

Quando três meses mais tarde, novos expedicionários seguiam para Canudos, depararam ainda o mesmo cenário: renques de caveiras branqueadas de velhos trapos, esgarçados nos ramos dos arbustos e, de uma banda, - mudo protagonista de um drama formidável - o espectro do velho comandante [...] (CUNHA, 2001, p. 254).

Quanto mais nos aproximamos do desfecho da obra, mais intensa se forma a imagem teatral. Sentimos a temperatura através da representação dos atores. O real beira a ficção ou vice-versa:

Atestadas de curiosos, todas as casinhas adjacentes à comissão de engenharia formavam a plateia enorme para a contemplação do drama. Assestavam-se binóculos em todos os rasgões das paredes. Aplaudiase. Pateava-se. Estrugiam bravos. A cena - real, concreta, iniludível aparecia-lhes aos olhos como se fora uma ficção estupenda, naquele palco revolto (CUNHA, 2001, p. 450-1). 
Em várias passagens o leitor/espectador tem a sensação e, às vezes, até certeza de que o drama chegou ao fim, de que os inimigos foram destruídos, ou de que a “insurreição estava morta” (CUNHA, 2001, p. 452). Porém, os insurgentes retornavam à luta com toda a força, surgiam do nada, aumentando o mistério que rondara a Campanha de Canudos.

A partir da narração dos "Últimos dias", devido aos atos de bravura dos jagunços, que defendiam o seu lar, fica mais evidente a mudança no julgamento do narrador sobre estes, como também o dos próprios soldados que "começaram a vê-lo heróico" (CUNHA, 2001, p. 455). Se antes Euclides expunha a barbárie de uma raça pouco evoluída, agora ele desmascara o civilizado. Os militares agem com requinte de crueldade, igualando-se ao seu oponente:

Agarravam-na pelos cabelos, dobrando-lhe a cabeça, esgargalando-lhe
o pescoço; e, francamente exposta a garganta, degolavam-na (p. 458).
(...) Tínhamos valentes que ansiavam por essas cobardias
repugnantes, tácita e explicitamente sancionadas pelos chefes
militares. Apesar de três séculos de atraso os sertanejos não lhes
levavam a palma no estadear idênticas barbaridades (CUNHA, 2001,
p. 459).

Nesta guerra, o homem atua como animal e devora o seu semelhante, principalmente sabendo que, "ademais, não havia temer-se juízo tremendo do futuro" (CUNHA, 2001, p. 463), frase que alude à desconfiança acerca da História. Apoiados em Le Goff (1984, p. 13), que relata o interesse dos grupos dominantes em registrar apenas o que lhes convêm; ou em Benjamin (1987, p. 225), que questiona a relação de empatia do investigador historicista com o vencedor, vemos que Euclides tinha consciência de que a História não registraria aquele massacre, de que a coletividade não teria uma voz que falasse por ela, e, é neste sentido que o porta-voz de Os sertões denuncia um crime:

E lá não chegaria, certo, a correção dos poderes constituídos. O atentado era público. Conhecia-o, em Monte Santo, o principal representante do governo, e silenciava. Coonestara-o com a indiferença culposa. Desse modo a consciência da impunidade, do mesmo passo fortalecida pelo anonimato da culpa e pela cumplicidade tácita dos únicos que podiam reprimi-la, amalgamou-se a todos os rancores acumulados, e arrojou, armada até os dentes, em cima da 
mísera sociedade sertaneja, a multidão criminosa e paga para matar (CUNHA, 2001, p. 464).

Abatidos pela fome e, principalmente, pela sede, os líderes da revolta ensaiam a entrega forjada dos "sobreviventes", mulheres, velhos e crianças em estado lastimável, roubando o brilho da cena da vitória: "os combatentes contemplavam-nos entristecidos. Surpreendiam-se; comoviam-se [...] a vitória tão longamente apetecida decaía de súbito. Repugnava aquele triunfo. Envergonhava” (CUNHA, 2001, p. 492).

O drama aproxima-se do fim. Não tendo mais com quem se preocupar, desafogados dos estorvos, os jagunços puderam entregar-se inteiramente à representação do seu último papel, o de heróis do sertão: "Canudos não se rendeu. Exemplo único em toda a História, resistiu até o esgotamento completo" (CUNHA, 2001, p. 497). Eternizou-se, portanto, por meio das metáforas euclidianas, pois não há como negar que Os sertões - narrado como drama - foi narrativa grandemente responsável pelo resgate de Canudos enquanto fato histórico marcante.

\section{Conclusão}

Buscamos perscrutar, nessas poucas páginas, a gênese da obra Os sertões, que teve como ponto de partida os artigos enviados por Euclides da Cunha ao jornal $O$ Estado de São Paulo, e que relatam seu testemunho na guerra de Canudos por meio da representação poético-ficcional adquirida quando aqueles relatos são atravessados pelo discurso literário.

Foi possível observar que a leitura de ambos os textos aqui analisados revela estratégias distintas. Enquanto o Diário se configura na folha de papel, Os sertões viaja mundos. Esse fenômeno é possível através da instituição literatura, que tem o poder de transformar o particular em universal. Canudos, em si, pode chamar a atenção de alguns poucos leitores, porém, o drama narrado em Os sertões diz respeito à humanidade, ou a grupo mais amplo de leitores, pois além da história em si, leva o homem a questionar os efeitos da guerra e de sua real necessidade.

A guerra que serviu de pano de fundo para a escrita de $O s$ sertões é a mesma que assola as sociedades "civilizadas" do século XXI: a intolerância e a invisibilidade do 
outro. Ainda existem muitos que acreditam na guerra e na violência como solução, convertendo a vida de inocentes em um drama real.

Assim, a história se repete, e muitos Canudos são resgatados do esquecimento, conforme vimos na alegoria do anjo benjaminiano e podem ser eternizados na literatura através do escritor/poeta e de suas metáforas.

\section{Referências bibliográficas:}

AZEVEDO FILHO, Leodegário A. de. A configuração do real em Euclides da Cunha. Rio de Janeiro: Tempo Brasileiro, 1996.

BENJAMIN, Walter. Sobre o conceito de história. In: Obras escolhidas I: magia e técnica, arte e política. 3. ed. São Paulo: Brasiliense, 1987, p. 222-232.

CUNHA, Euclides da. Canudos: Diário de uma expedição. In: . Obra completa, v. 2. Rio de Janeiro: Aguilar, 1966.

Os sertões: campanha de Canudos. 3. ed. São Paulo: Ática, 2001.

GALVÃO, Walnice Nogueira. Euclides da Cunha. In: PIZARRO, Ana. América Latina: palavra, literatura e cultura, v. 2. São Paulo: UNICAMP, 1994, p. 615-633.

HERNÁNDEZ, Juan Antonio. Los residuos salvajes: multitud y máquina de guerra en Los Sertones de Euclides da Cunha. Revista Iberoamericana, v. LXX, n. 207, p. 443-453, abr.-jun. 2004.

LE GOFF, Jacques. Memória. In: ROMANO, R. (Dir.). Enciclopédia Einald, v. 1. Memória- História. Porto: Imprensa Nacional ; Casa da Moeda, 1984, p. 11-50.

NEPOMUCENO, Luís André. A força motriz da História (uma visão de Euclides da Cunha). Remate de Males, Campinas, SP, n. 13, p. 47-55, 1993.

NOGUEIRA, Ataliba. Antônio Conselheiro e Canudos: revisão histórica. São Paulo: Companhia Editora Nacional, 1974. p. 175-182.

PRADO, Antônio Arnoni. Ficção e verdade n' Os Sertões. Remate de Males, Campinas, SP, n. 13, p. 25-29, 1993.

PROENÇA, M. Cavalcanti. O monstruoso anfiteatro. In: Estudos literários. Rio de Janeiro: José Olímpio, 1971, p. 251-267.

WHITE, Hayden. Trópicos do discurso: ensaios sobre a crítica da cultura. São Paulo: EDUSP, 1994. 
Artigo recebido em: 05 de julho de 2012.

Artigo aprovado em: 31 de outubro de 2012.

\section{Sobre a autora:}

Doutora em Literatura Hispano-Americana (UFRJ / 2008), Mestre em Letras Neolatinas (UFRJ/2003) e Especialista de Língua Espanhola e Culturas Hispânicas (UFES/1998). Atualmente é professora adjunta II de Língua e Literaturas Hispânicas; Coordenadora do Curso de Letras - Espanhol e Diretora do Instituto Ágora, na UFRN/RN. 